\title{
Effects of no mating on the female adults and embryonic development of Schistocerca gregaria (Orthoptera: Acrididae)
}

\author{
WANG FangHai ${ }^{1,2 *} \&$ SEHNAL František ${ }^{2}$ \\ ${ }^{1}$ Institute of Entomology \& State Key Laboratory for Biocontrol, Sun Yat-sen University, Guangzhou 510275, China; \\ ${ }^{2}$ Institute of Entomology, Academy of Sciences, Branišovská 31, 37011 České Budějovice, Czech Republic
}

Received September 25, 2012; accepted December 14, 2012; published online June 4, 2013

\begin{abstract}
The newly emerged adult females of Schistocerca gregaria were separated and kept in the rearing conditions without males to examine the detailed developmental characteristic of the no mating females and carefully observed the developmental progress of non-fertilised eggs laid by virgin females. The results showed that the females kept without males survived in average $43 \mathrm{~d}$, i.e. $58 \%$ of the life span of mated controls, and laid correspondingly fewer egg pods. The size of egg batches, the weight of eggs, and their content of ecdysteroids were normal but the hatch rate was reduced to $18.27 \%$. Blocks of early embryogenesis $(58.43 \%)$ and hatching failures (23.29\%) were the major causes of death. Moreover, most of the hatched insects died during the postembryonic development and only a few females reached the adult stage. All insects that developed until the penultimate or last larval instar or reached the adult stage were females.
\end{abstract}

virgin, life span, ecdysone, embryogenesis, locusts, parthenogenesis

Citation: Wang F H, Sehnal F. Effects of no mating on the female adults and embryonic development of Schistocerca gregaria (Orthoptera: Acrididae). Chin Sci Bull, 2013, 58: 3244-3247, doi: 10.1007/s11434-013-5867-2

The primary purpose of mating in most insects is the transfer of sperm and secretions of the male accessory glands in to females for procreation. Mating has been shown to directly affect female life span, egg production rate, female fertility, etc. [1]. Frequency of mating depends on the life styles of insects. The desert locust, Schistocerca gregaria, is a disaster pest in the world. It has two morphisms: solitary and gregarious. Since solitary locusts live alone and avoid others, chances to find a suitable mate are less. So what kind of developmental fate and characteristic are there for no mating females and the eggs laid by them? No detailed reports can answer the question until now.

In our established gregarious culture of $S$. gregaria, where females had 110-130 ovarioles and deposited up to 6 egg pods, with 45-55 eggs each of which about $16 \%$ did not develop because of un-fertilization [2,3]. In this study, we used these locust line and artificial controled their mating

*Corresponding author (email: 1sswfh@mail.sysu.edu.cn) behavior to determine the developmental fate and characteristics of virgin females that do not find a mate and therefore produce unfertilized eggs and the developmental progress of non-fertilised eggs laid by them. This will be helpful to understand the characteristics of solitary locust more detailed and to find a new way or method to control the pest efficiently in the future.

\section{Materials and methods}

Gregarious culture of the desert locust, Schistocerca gregaria (Forskål), was maintained at $30^{\circ} \mathrm{C}$ and $12 \mathrm{~h}$ photoperiod as described by $\mathrm{Li}$ et al. [4]. Newly emerged adult females were removed from the rearing cage into a separate container. Cages with adult locusts (both sexes or only females) were provided with plastic tubes $(10 \mathrm{~cm}$ long and 5 $\mathrm{cm}$ in diameter) filled with sterile moist sand, where the females deposited their eggs. Tubes with the egg pods were 
removed from the breeding cages and covered with a polypropylene foil to retain high humidity. They were kept in dark in a thermostat until the hatching time and were inspected.

To examine the embryos, eggs were soaked in $3 \%$ sodium hypochlorite until the eggshell became transparent and then rinsed in distilled water. Developmental stage of embryos was assessed according to Shulov and Pener [5] and Tyrer [6]. Ecdysteroids were quantified in the egg homogenates as described previously [7], using antiserum 85-B/L2 from Dr. P. Maróy. [23,24- $\left.{ }^{3} \mathrm{H}\right]$ ecdysone (New England Nuclear, specific activity $3.3 \mathrm{Tbq} / \mathrm{mmol}$ ) was used as ligand and 20-hydroxyecdysone (20E) as a reference standard. The ecdysteroid content was expressed in ng $20 \mathrm{E}$ equivalents per egg.

All the statistical analyses were performed using $\mathrm{Su}$ perANOVA [8]. Data was reported as mean \pm S.E.

\section{Results}

\subsection{Developmental characteristic of non-mated virgin females}

Data in Table 1 demonstrated that mating had positive effect on female survival and fertility. Life span of females reared without males was $60 \%$ shorter than those with males. Similarly, hatch rate was significantly reduced in eggs laid by un-fertilized females (Table 1), while the number of eggs per pod, egg weight, and ecdysteroid content were similar between the two groups. The oviposition patterns of the fertilised and non-fertilised females were initially similar followed by a reduction in the number of deposited egg pods in the non-fertilised females which may be due to their shorter life (Figure 1).

\subsection{Developmental process of the eggs from non-mated females}

Development of individual eggs differed considerably. In some of the egg pods, no embryo completed development to hatching ( $0 \%$ hatch rate), while in some as many as $73 \%$ of them hatched successfully (Table 2). Dissections of the non-developing eggs revealed that their development ceased at various stages of embryogenesis (data not shown). Death also occurred frequently at the time of hatching: some larvae failed to escape from the eggshell, while others perished when attempting to shed off the embryonic exuvia. Most of the eclosed larvae died in different larval instars and only very few (about $0.23 \%$ ) managed to develop until the adult stage. All insects that developed until the penultimate or last larval instar or reached the adult stage were females.

\section{Discussion}

\subsection{Low egg production rate in virgin females}

The effect of mating that results in increased female egg production rate, has been reported in many insects, such as Requena verticalis [9], Drosophila melanogaster [10], Coelopa frigida [11], Phthorimaea operculella [12] and Chrysochus cobaltinus [13]. It has been reasoned that stimulation of female egg production by mating usually resulted from one or more of three factors: the act of mating per se, presence of sperm and transfer of accessory substances [1]. In this study, there was a marginal increase in the number of egg pods laid by mated females (5.6)

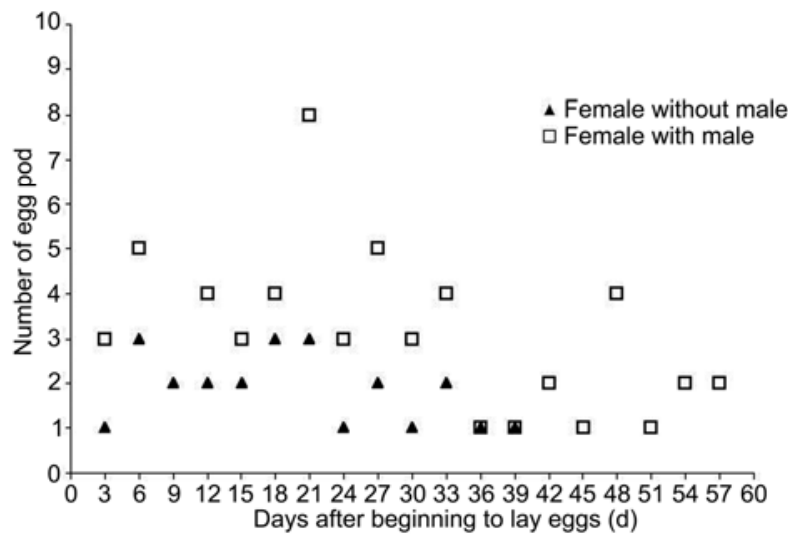

Figure 1 Numbers of egg pods deposited during the entire lifetime by ten females kept alone (solid triangles) and by ten females kept with equal number of males (empty squares).

Table 1 Performance (mean \pm S.E.) of females reared with or without males from the first day after emergence ${ }^{\text {a) }}$

\begin{tabular}{ccc}
\hline Parameter & Only females, no males & Females and males \\
\hline Insect number & $10 q$ & $10 q+10{ }^{\star}$ \\
Total egg pods/female & 3 & 5.6 \\
Mislaid egg pods/female & 0.375 & 2 \\
Eggs per one pod & $44.60 \pm 3.23 \mathrm{a}$ & $9.03 \pm 2.12 \mathrm{a}$ \\
Weight of fresh egg in mg & $9.51 \pm 0.12 \mathrm{a}$ \\
Hatch rate (\%) & $18.07 \pm 5.96 \mathrm{a}$ & $79.15 \pm 3.71 \mathrm{~b}^{*}$ \\
Life span (days) & $43.13 \pm 2.86 \mathrm{a}$ & $74.40 \pm 2.96 \mathrm{~b}^{*}$ \\
Number of ovarioles/female & $111.30 \pm 2.19 \mathrm{a}$ & $121.90 \pm 4.47 \mathrm{a}$ \\
Ecdysteroid content (ng/egg) & $101.01 \pm 10.46$ & $129.71 \pm 12.64 \#$ \\
\hline
\end{tabular}

a) $* P<0.0001$, extremely significant. $\# P=0.0823$, marginally significant. The different alphabet after the number means significant. Mislaid egg pods mean that the pods were not laid in the tube provided for female adults to lay eggs. Ecdysteroid content was assayed on day 2 after egg laying. 
Table 2 Development of 15 egg pods from females reared without males ${ }^{\text {a) }}$

\begin{tabular}{|c|c|c|c|c|c|c|c|c|c|c|c|}
\hline Egg pod & No. of egg & $\begin{array}{c}\% \\
\text { Early death }\end{array}$ & $\begin{array}{c}\% \\
\text { Pharate } \\
\text { death }\end{array}$ & $\begin{array}{c}\% \\
\text { Hatch }\end{array}$ & $\begin{array}{c}\% 1 \\
\text { Instar }\end{array}$ & $\begin{array}{c}\% 2 \\
\text { Instar }\end{array}$ & $\begin{array}{c}\% 3 \\
\text { Instar }\end{array}$ & $\begin{array}{c}\% 4 \\
\text { Instar }\end{array}$ & $\begin{array}{l}\% 5 \\
\text { Instar }\end{array}$ & $\%$ Adult & Sex \\
\hline 1 & 33 & 75.76 & 12.12 & 12.12 & 3.03 & 0 & 0 & 0 & 0 & 0 & \\
\hline 2 & 17 & 76.47 & 11.76 & 11.76 & 23.44 & 6.25 & 6.25 & 6.25 & 1.56 & 0 & q \\
\hline 3 & 47 & 48.94 & 12.77 & 38.30 & & & & & & & \\
\hline 4 & 44 & 9.09 & 68.18 & 22.73 & 22.73 & 4.55 & 0 & 0 & 0 & 0 & \\
\hline 5 & 57 & 54.39 & 38.60 & 7.02 & 7.02 & 0 & 0 & 0 & 0 & 0 & \\
\hline 6 & 52 & 19.23 & 7.69 & 73.08 & 32.22 & 7.78 & 3.33 & 2.22 & 2.22 & 0 & q \\
\hline 7 & 38 & 26.32 & 63.16 & 10.53 & & & & & & & \\
\hline 8 & 63 & 19.05 & 15.87 & 65.08 & 25.40 & 11.11 & 9.52 & 9.52 & 7.94 & 1.59 & ㅇ \\
\hline 9 & 32 & 75 & 15.63 & 9.38 & 4.90 & 2.94 & 2.94 & 2.94 & 2.94 & 0.98 & $q$ \\
\hline 10 & 38 & 94.74 & 5.26 & 0 & & & & & & & \\
\hline 11 & 32 & 62.5 & 31.25 & 6.25 & & & & & & & \\
\hline 12 & 49 & 100 & 0 & 0 & 0 & 0 & 0 & 0 & 0 & 0 & \\
\hline 13 & 25 & 64 & 36 & 0 & 0 & 0 & 0 & 0 & 0 & 0 & \\
\hline 14 & 39 & 97.44 & 2.56 & 0 & 0 & 0 & 0 & 0 & 0 & 0 & \\
\hline 15 & 28 & 53.57 & 28.57 & 17.86 & 17.86 & 0 & 0 & 0 & 0 & 0 & \\
\hline Mean \pm S.E. & $39.6 \pm 3.23$ & $58.43 \pm 7.62$ & $23.29 \pm 5.40$ & $18.27 \pm 5.95$ & $12.42 \pm 3.64$ & $2.97 \pm 1.19$ & $2.00 \pm 0.98$ & $1.90 \pm 0.97$ & $1.33 \pm 0.74$ & $0.23 \pm 0.16$ & \\
\hline
\end{tabular}

a) The data about larval stages were combined together in some egg pods because they were laid in the same tube, such as Nos. 2 and 3; Nos. 6 and 7; Nos. 9, 10 and 11; "Early death" means that the egg died at various stages of embryogenesis before hatching; "Pharate death" means that the egg died at the time of hatching.

versus those laid by virgin females (3) of S. gregaria. In addition increase in the number of eggs per pod between mated females (49.03) and virgin (44.6) was also obvious. However, we did observed an increase in the life span of mated females by about $31 \mathrm{~d}$ which would allow more time for egg maturation and the number of egg laid by mated females than virgin females, that could contribute to an increase in female egg production.

\subsection{Reduced female life span in virgin females}

The no mating female life span was $43.13 \mathrm{~d}$, much less than mating female life span, $74.40 \mathrm{~d}$, in $S$. gregaria. This phenomenon was also reported in many species, for example, Gryllus veletis [14], Pieris napi [15]. One of reasons to increase mating female life span is the large number of accessory substances transferred to females with the male ejaculate $[14,15]$. While the solitary virgin desert locusts could not get any accessory substances from males, this may be cause them had a relatively shorter longevity.

\subsection{Low egg hatch rate and parthenogenesis}

The hatch rate of no mating female's eggs was 18.07\%, while that of mating female's eggs was $74.40 \%$. Alhough the hatch rate of no mating female's eggs was low, some eggs indeed can develop to 5 instar larvae or adults, it showed that parthenogenesis happened in our gregarious culture of $S$. gregaria.

Parthenogenesis has been found in almost all insect orders except Odonata and a few small orders [16]. In the case of facultative parthenogenesis, which occurs in several spe- cies of locusts $[17,18]$ and various other insects, the eggs can develop with or without fertilisation. Facultative parthenogenesis was recently studied in detail in the cockroach Nauphoeta cinerea by Corley et al. [19]. It was found that only a few females had the ability to switch from making eggs that do not develop without fertilisation to the production of zygotes that develop in the absence of sperm. The development of non-fertilised eggs was usually interrupted shortly after the initiation of embryogenesis, presumably as a consequence of the duplication of chromosomes that carried recessive lethal mutations. The homozygosity of the maternal chromosome set, which is typical for the automictic (meiotic) parthenogenesis, is probably the major cause of developmental disturbances. Abnormal deposition of the maternal and lack of the paternal determinants is another probably source of developmental defects.

The observations on $N$. cinerea are in good agreement with our results. We found that the developmental capacities of eggs laid by virgin females differed considerably. No embryo completed development to hatching in some of the egg pods $(0 \%$ hatch), while in others more than $70 \%$ of them successfully hatched (Table 2). Developmental block occurred mostly at a very early stage, as expected in the case of severe genetic defects. The rate of embryonic development did not seem to be altered until the stage when it came to a halt. The death was secondary and occurred in some cases long after the controls had hatched. Other insects died at hatching or during larval development, often as a consequence of ecdysial failures. These insects probably perished because certain functions controlled by the mutated genes could not be properly exercised.

A few daughters of virgin females survived in our ex- 
periments until the adult stage and were probably able to establish parthenogenetic line as described by Schmidt [17]. Their survival apparently depended on the elimination of recessively lethal genes whose effect had been overcome in the original bisexual population by the wild alleles provided by the sperm. Only exceptionally may crossing-over recombination during oocyte meiosis yield a genome deprived of the life-threatening mutations and this explains the paucity of successful progeny development in the first parthenogenetic generation. Enormous variation in the developmental fate of eggs from different egg pods can be explained by differences in the genetic load of individual females. Duplication of the maternal haploid genome included the $\mathrm{X}$ chromosome and thereby determined exclusively female sex of the progeny.

We cordially acknowledge the gift of the antiserum from Dr. P. Maroy, the University of Szeged, Hungary. This study was supported by the Grant Agency of the Czech Republic (522/98/0773), the National Natural Science Foundation of China (39870475 and 31171844), the Natural Science Foundation of Guangdong Province (S2011010001353).

1 Arnqvist G, Nilsson T. The evolution of polyandry: Multiple mating and female fitness in insects. Anim Behav, 2000, 60: 145-164

2 Sláma K. Correlation between metabolic depression and ecdysteroid peak during embryogenesis of the desert locust, Schistocerca gregaria. Eur J Entomol, 2000, 97: 141-148

3 Wang F H, Sehnal F. Ecdysteroid agonist RH-2485 injected into Schistocerca gregaria (Orthoptera: Acrididae) females accelerates oviposition and enhances ecdysteroid content in eggs. Appl Entomol Zool, 2002, 3: 409-414

4 Li W W, Vedrová A, Sehnal F. Humoral stimulation of the larval and adult prothoracic glands in Schistocerca gregaria. Arch Insect Biochem, 1997, 36: 85-93
5 Shulov A, Pener M P. Studies on the development of eggs of the desert locust and its interruption under particular conditions of humidity. Anti-locust Res Bull, 1963, 41: 1-59

6 Tyrer N M. Quantitative estimation of the stage of embryonic development in the locust, Schistocerca gregaria. J Embryol Exp Morphol, 1970, 23: 705-718

7 Wang F H, Sehnal F. Effects of the imidazole derivative KK-42 on the females and embryos of Schistocerca gregaria. Entomol Sci, 2001, 4: 387-392

8 Anon. SuperANOVA. Berkeley, CA: Abacus Concepts, Inc, 1989

9 Gwynne D T. Courtship feeding increases female reproductive success in bushcrickets. Nature, 1984, 307: 361-363

10 Chapman T, Liddle L F, Kalb J M, et al. Cost of mating in Drosophila melanogaster females is mediated by male accessory gland products. Nature, 1995, 373: 241-244

11 Dunn D W, Sumner J P, Goulson D. The benefits of multiple mating to female seaweed flies, Coelopa frigida (Diptera: Coelpidae). Behav Ecol Sociobiol, 2005, 58: 128-135

12 Makee H, Saour G. Factors influencing mating success, mating frequency, and fecundity in Phthorimaea operculella (Lepidoptera: Gelechiidae). Environ Entomol, 2001, 30: 31-36

13 Schwartza S K, Peterson M A. Strong material benefits and no longevity costs of multiple mating in an extremely polyandrous leaf beetle, Chrysochus cobaltinus (Coleoptera: Chrysomelidae). Behav Ecol, 2006, 17: 1004-1010

14 Burpee D M, Sakaluk S K. Repeated matings offset costs of reproduction in female crickets. Evol Ecol, 1993, 7: 240-250

15 Karlsson B. Nuptial gifts, resource budgets, and reproductive output in a polyandrous butterfly. Ecology, 1998, 79: 2931-2940

16 Mittwoch U. Parthenogenesis. J Med Genet, 1978, 15: 165-181

17 Schmidt G H, Albutz R. Laboratory studies on pheromones and reproduction in the desert locust Schistocerca gregaria (Frosk.). J Appl Entomol, 1994, 4-5: 378-391

18 Hawkins E, Smith W, O'Donnell M J. Measurements of ooplasmic pCa in fertilized eggs of the locust, Locusta migratoria, and a role for external calcium in experimental activation of unfertilised eggs. Invertebr Reprod Dev, 1998, 2-3: 165-172

19 Corley L S, Blankenship J R, Moore A J, et al. Developmental costraints on the mode of reproduction in the facultatively parthenogenetic cockroach Nauphoeta cinerea. Evol Dev, 1999, 2: 90-99

Open Access This article is distributed under the terms of the Creative Commons Attribution License which permits any use, distribution, and reproduction in any medium, provided the original author(s) and source are credited. 